\title{
PROTEIN INTERACTIONS OF GENTISIC ACID AND CERTAIN OF ITS OXIDATION PRODUCTS ${ }^{1}$
}

\author{
By BETTY S. ROOF 2 AND JOSEPH C. TURNER \\ (From the Department of Medicine, Columbia University College of Physicians and Surgeons, \\ and the Presbyterian Hospital in the City of New York)
}

(Submitted for publication June 14, 1955 ; accepted July 28, 1955)

Although salicylate was introduced eighty years ago in the treatment of rheumatic fever (1), the mechanism of its effect is still unknown. Speculation concerning the mode of action of salicylate and its congeners has run from considerations of one or another of the physico-chemical properties of phenolic acids to a supposed effect on the pituitary-adrenal axis (2-4). In a recent study of tissue interactions of certain salicylic acid derivatives, Helander attempted to demonstrate selective localization of sodium salicylate in connective tissue using fluorescence microscopy but was unable to do so (5). From his investigations he concluded that attachment of both a carboxyl- and an amino- group to the aromatic ring is necessary for connective tissue binding. These investigations did not include gentisic acid, a diphenol which takes on special importance because in the human subject as well as in animals an appreciable portion of administered salicylate ( 5 to 8 per cent) is oxidized and excreted as gentisate $(6-8)$.

Numerous workers (9-12) have now confirmed the observation of Meyer and Ragan in 1948 (8) that gentisate has an antirheumatic effect entirely comparable to that of salicylate itself. The present report concerns the affinity of gentisic acid and its oxidation products for connective tissue, an experimental approach to the hypothesis that oxidation of the antirheumatic phenols is essential to their action.

\section{METHODS}

Observations on distribution of gentisic acid using its fluorescence in ultra-violet light. Sodium gentisate was prepared in distilled water in concentrations of 0.5 to 5.0 per cent. Mice were injected with $1.0 \mathrm{ml}$. intra-

1 This study was supported in part by a grant from the U. S. Public Health Service (C-2473), and by a gift from the New York Chapter of the Arthritis and Rheumatism Foundation.

${ }^{2}$ Clinical Fellow of the American Cancer Society. Present address: Dept. of Medicine, Massachusetts General Hospital, Boston, Mass. venously and sacrificed at intervals. Dissection and observation were carried out in the near ultra-violet light (Hanovia Inspectolite, wave-length maximum 3,660 $\AA$ ).

Equilibrium dialysis. The method used by Taggart (13) was employed, with the following modifications: Dialysis was carried out at $0^{\circ}$ C., and tubes were inverted frequently rather than shaken constantly. Duplicate determinations were made, gentisic acid being added in one instance to the inside of the cellophane bag and in the second to the buffer on the outside. Equilibrium was attained in 24 hours. Buffer was $0.067 \mathrm{M}$ sodium phosphate, $\mathrm{pH} 7.0$ and 7.5 , in $0.05 \mathrm{M} \mathrm{NaCl}$, except when procollagen was tested. In this case acetate buffer $\mathrm{pH} 4.0$ was used. Gentisic acid was determined by the method of Roseman and Dorfman (14).

Tissue Extracts. Procollagen was prepared from rat tails by the method of Oriekwovitch (15). Beef tendomucoid was extracted according to the method of Bergmann and Stein (16). "Chondromucoid" from beef was prepared according to the method given in Hawk, Oser, and Summerson (17). Gelatin-chondroitin sulfate was generously provided by Dr. Karl Meyer of this Department.

Oxidation in air of gentisate. A 7.5 per cent solution of sodium gentisate in phosphate buffer $0.05 \mathrm{M} \mathrm{pH} 7.5$ in Erlenmeyer flasks plugged with cotton was shaken at $37^{\circ}$ C. for 18 to 24 hours. No bacterial growth was found.

Oxidation in air of gentisate with added tissues and particles. Solutions of sodium gentisate in phosphate buffer $0.05 \mathrm{M}, \mathrm{pH} 7.5$, were prepared in concentrations ranging from 20 to $0.04 \mathrm{mg}$. per cent. To $15 \mathrm{ml}$. of the solutions were added in separate experiments pieces of 1 ) dried collagen, about $150 \mathrm{mg}$; 2) hide powder, about 100 to $125 \mathrm{mg}$; 3) cartilage powder, about $450 \mathrm{mg}$; 4) non-nutritive cellulose; 5) sand; 6) filter paper particles; 7) mouse hair; 8) epilated mouse skin $0.5 \mathrm{~cm} . \times$ $0.5 \mathrm{~cm}$. These flasks were shaken for 3 hours at $37^{\circ} \mathrm{C}$.

Collagen was prepared by the method of Einbinder and Schubert (18). Cartilage powder and hide powder were commercially available. The non-nutritive cellulose used was that of the Nutritive Biochemical Corp.; the filter paper No. 1 Whatman cut into $0.5 \times 0.5 \mathrm{~cm}$. squares.

Serum fractionation. Globulin was precipitated from human serum by the addition of $\mathrm{Na}_{2} \mathrm{SO}_{4} 22$ per cent w/v. Globulin and albumin were dialyzed continuously against phosphate buffer until no further $\mathrm{SO}_{4}^{--}$could be detected in the dialysate. 
Exhaustive dialysis of oxidation products of gentisic acid. A 7.5 per cent solution of sodium gentisate in phosphate buffer $\mathrm{pH} 7.5,0.05 \mathrm{M}$, was shaken at $37^{\circ} \mathrm{C}$. until no further increase in brown color occurred, as indicated by constant optical density. To $4.0 \mathrm{ml}$. of this solution was added 1) albumin content of $1.0 \mathrm{ml}$. of serum; 2) globulin obtained from $1.0 \mathrm{ml}$. of serum; 3) phosphate buffer. To $4.0 \mathrm{ml}$. of the oxidized gentisate was added 1) $1.0 \mathrm{ml}$. of serum;2) $3.0 \mathrm{ml}$. of 7.0 per cent gelatin solution. All were then brought to $7.0 \mathrm{ml}$. with phosphate buffer. Five ml. of each of these combinations were placed in cellophane bags and dialyzed in the cold against frequent changes of phosphate buffer $\mathrm{pH} 7.5$, $0.05 \mathrm{M}$, until all gentisic acid had been removed from the bag as shown by lack of fluorescence of the dialysate.

Paper electrophoresis. Separations were carried out using phosphate buffer $\mathrm{pH} 7.5, \mathrm{I} / 2=0.1$, on Wnatman paper No. 3 in a lucite chamber, 12 to 15 volts per $\mathrm{cm}$. paper, for a run of 3 to 4 hours. Papers were examined in daylight and in the ultra-violet.

RESULTS

\section{The in vivo affinity of gentisate for connective tissues}

The distribution of gentisic acid following oral or intravenous administration has not been studied previously. In ultra-violet light, gentisic acid displays a striking bluish-white fluorescence so intense that detection of trace amounts is possible (19). After intravenous injection into mice fluorescence of the connective tissues could readily be appreciated and was greatest in skin, tendons, bones, and cartilages (Figures 1 and 2).

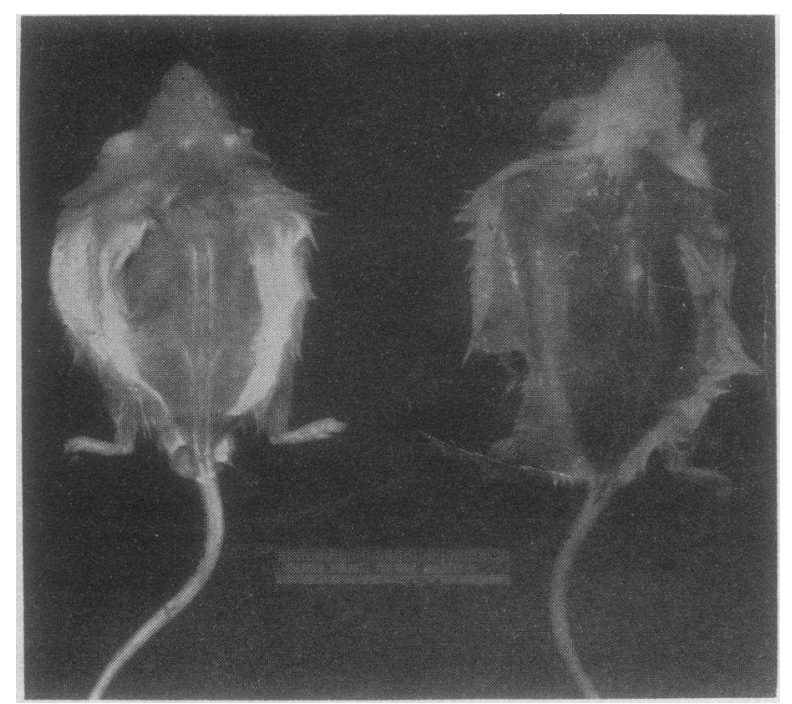

Fig. 1. Fluorescence of Subcutaneous Tissues 30 Minutes after Intravenous Gentisate-Control Mouse on THE Right
Gentisic acid is excreted rapidly in the urine. In keeping with this, the fluorescence of the skin and the tendons largely disappeared within two hours. However, cartilages and bones retained the whitish fluorescence for 5 to 6 hours and sometimes longer, perhaps largely because these structures have a meager blood supply, although the possibility may be allowed that a somewhat firmer attachment of the drug could also contribute to its persistence in these tissues. In any case, if the distribution of fluorescence may be taken to reflect binding of gentisate by connective tissues, the interaction appears to be easily reversible.

\section{Binding of gentisate in vitro}

A first approximation to the study of the in vitro binding of gentisate by tissues was made by exposing slivers of pigs' knuckles and pieces of cartilage, muscle, liver, kidney, and tendon from freshly sacrificed mice to 1 per cent solutions of sodium gentisate for 30 minutes and then washing them briefly in running tap water. Fluorescence could now be demonstrated in each fragment. Immersion in saline for several hours resulted in disappearance of fluorescence from all tissues except cartilage and tendon.

With equilibrium dialysis no binding of gentisate could be demonstrated for any of the following tissue extracts: beef tendomucoid, beef chondromucoid, rat procollagen, 1 per cent gelatin, 1 per cent gelatin plus heparin, 1 per cent gelatin plus glycogen. Suspensions of an insoluble gelatinchondroitin sulfate complex did not bind gentisate. nor did suspensions of hide powder, or collagen powder.

However, considerable binding of gentisic acid by both human and bovine serum albumin was found in molar ratios corresponding to those that mark the interaction of many pharmacologic agents, e.g., salicylate, with serum albumin (20). At concentrations of free gentisate $10^{-3}$ molar, using 65,000 as molecular weight of albumin, about 3 moles of gentisate were bound per mole of albumin. The amount of serum albumin present accounted for all the binding by serum. All of the gentisic acid could be removed by exhaustive dialysis.

Serum albumin was thus the only protein, soluble or insoluble, to bind gentisic acid in vitro in measurable amounts. 


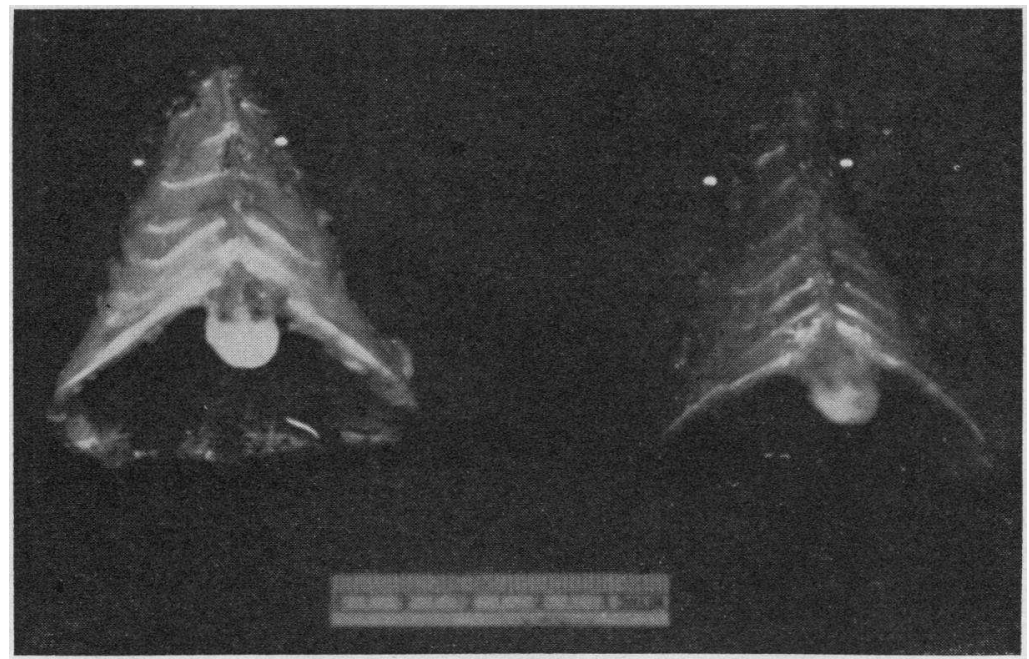

Fig. 2. Rat Thoracic Cage to Show Fluorescence of Bone and CartiLage after Intravenous Gentisate-Control on Right

Binding of oxidation products of gentisic acid by proteins

Gentisic acid is the reductant in an oxidationreduction system $\left[\mathrm{E}_{0}{ }^{3} 0.796\right.$ m.v. at $\mathrm{pH} 0.028$ (21)] of which the oxidant, gentisoquinone, is unstable and has not been isolated. Gentisate is readily oxidized in air at neutral $\mathrm{pH}$ to brown or reddish brown pigments, presumably quinone which has in some part polymerized. The reaction appears to reach an end point after about 24 hours of vigorous shaking at $37^{\circ} \mathrm{C}$. Since the oxidation products have not been identified and suitable methods for their measurement do not exist, it is not possible to provide accurate data on the amounts of gentisate that may be oxidized. Under the experimental conditions and at neutral $\mathrm{pH}$, most of the gentisate ( \pm 90 per cent) probably remained in the reduced form. The presence of pigmented oxidation products can be easily appreciated by the eye in dilute solutions of gentisate in the range of $10^{-6}$ to $10^{-5}$ molar.

When pieces of dried collagen or hide powder were shaken with solutions of gentisate at $\mathrm{pH} 7.5$, definite pink to reddish brown coloration of the proteins could be noted within three hours. This pigmentation was detectable at concentrations of gentisate as low as $0.08 \mathrm{mg}$. per cent $\left(5 \times 10^{-6}\right.$ $\mathrm{M})$, and was not removed by washing in running tap water for 24 hours or by treatment with or-

\footnotetext{
${ }^{3} \mathrm{E}_{0}=$ electrode potential at 50 per cent reduction.
}

ganic solvents. Controls containing non-protein particles failed to show pigmentation.

\section{Application of paper electrophoresis to the separa- tion of oxidation products of gentisate}

Solutions of gentisic acid were subjected to electrophoresis on paper, both before and after oxidation in air. The findings were interpreted in terms of the appearance in visible and in ultraviolet light and after spraying with phenol reagents.

Fresh solutions of gentisate appeared to be electrophoretically homogeneous, showing a rapidly moving spot giving whitish fluorescence. After oxidation a more complex but remarkably characteristic and constant pattern could be seen, marked by five separate components. In the ultra-violet there were four discrete spots, viz., (a) a bright yellow spot which remained at the base line; (b) that of gentisate itself; (c) a small orange spot ahead of (b) ; and (d) a yellow spot which moved fastest of all (Figure 3). All of these areas could be stained with ammoniacal silver nitrate. In daylight there could be appreciated only (e) a single brown spot which overlay the front of the gentisate area.

Electrophoresis was carried out on control solutions of gentisate which had been both oxidized in air and exhaustively dialyzed. Only the brown spot (e above) was detectable, i.e., only one of the components seemed to be non-dialyzable. It had 


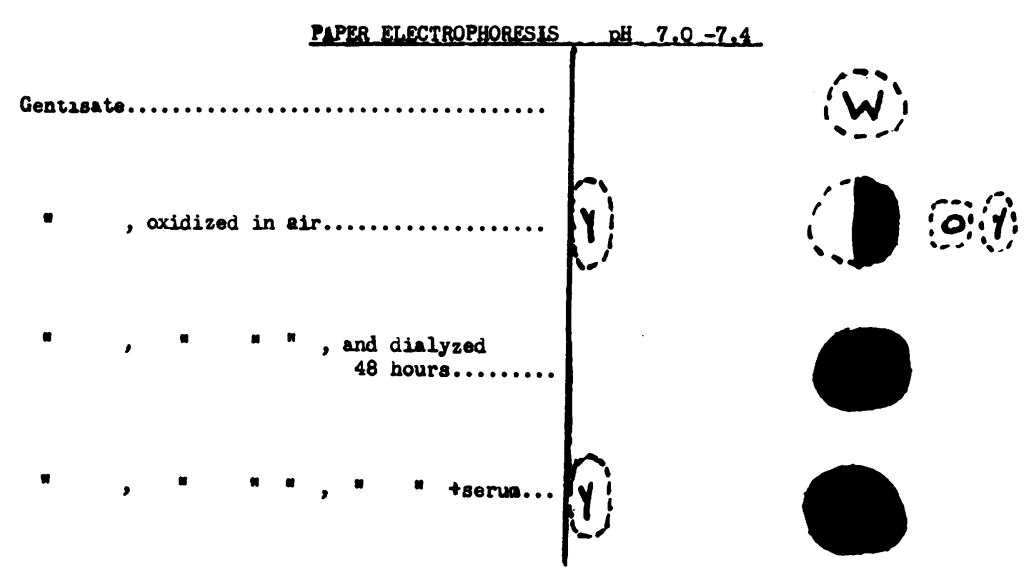

Fig. 3. Schematic Diagram of Electrophoretic Pattern of Components of Oxidation Products of Gentisate-See Text

appeared from the earlier experiments noted above that pigmented oxidation products were bound to proteins. Now it became of interest to see if any other of the electrophoretically separable materials might also interact with protein in a similar fashion.

Accordingly, albumin, globulin, and gelatin were added to solutions of gentisate and submitted to exhaustive dialysis. Subsequent electrophoresis showed that one of the fluorescent materials, represented by spot (a), was rendered non-dialyzable in the presence of any of these proteins, i.e., was presumably firmly bound.

\section{DISCUSSION}

Gentisate appears to be bound to some degree by living connective tissues, perhaps especially by cartilage and bone. No binding could be shown for fibrous proteins rendered soluble by various means, any of which may have been extreme enough to destroy the chemical affinities possessed by living tissue. It is, of course, possible that the apparent binding to the tissues in vivo was due to the presence of extravascular plasma albumin, estimated to make up as much as 50 per cent of the total albumin in the body (22). On this view, failure of solid protein preparations such as collagen powder to bind gentisate could be attributed to loss of albumin in the processing.

On the other hand, any appraisal of the chemical activity of gentisate must consider the ease with which it is oxidized and the reactivity of the oxi- dation products. It has been shown that oxidation products of gentisate can be separated electrophoretically into four distinct components and at least two of these appear to form complexes with proteins that are not readily dissociated in vitro.

It might be objected that these oxidation products are unlikely to form in vivo because of the poising action of the tissue elements. In this respect it is of interest to compare the oxidationreduction system of gentisic acid to that of homogentisic acid; the electrode potentials are comparable $(21,23)$. In the ochronosis of alkaptonuria $(24,25)$ the blackness of the cartilages, sclerae, and tendons is ascribed to oxidation products of homogentisic acid (23). In his original description of this disorder Virchow (25) remarked on the curious distribution of the ochre pigment, i.e., its predilection for the connective tissues, and pointed out that most prominent among these were cartilage and bone which have almost no blood supply. Fishberg and Dolin (23) comment that "these are the regions where there can be no poising effect of hemoglobin. Hence the quinone from the homogentisic acid can be formed." These views could be applied with equal force to gentisic acid. It should also be pointed out that in alkaptonuria the blood concentrations of homogentisic acid may be no higher than 1 to $3 \mathrm{mg}$. per cent (26), while after oral administration of gentisic acid serum levels as high as 15 to $30 \mathrm{mg}$. per cent may be obtained (27). 
It is noteworthy that quinones of gentisic acid inhibit hyaluronidase (28-30). This fact provides another suggestion that gentisic acid and its oxidation products may influence the metabolism of connective tissues. While direct evidence for the idea that oxidation of the phenols, perhaps to quinones, is important for their anti-inflammatory effect will be difficult to obtain yet the findings so far are consistent with this view, and it does appear that the affinity for connective tissue of gentisate and its oxidation products exceeds that of salicylate itself.

\section{SUMMARY}

1. After intravenous injection gentisate is excreted rapidly and soon disappears from most organs except the skeletal connective tissues, in which it remains for a considerable time.

2. In vitro binding of gentisate by various proteins demonstrated an attachment to serum albumin in the molar ratios that characterize other cations of similar molecular size.

3. Oxidation products of gentisate can be separated electrophoretically into at least four distinct components. Some of these appear to be firmly bound not only by serum albumin but also by insoluble connective tissue proteins, e.g., collagen.

4. It is suggested that the mode of action of the antirheumatic phenols may involve their oxidation in vivo to quinones which interact with connective tissue, i.e., that there is an analogy to the metabolism of homogentisic acid in the alkaptonuric.

\section{ACKNOWLEDGMENT}

The chemicals used in this study have been in part supplied through the generosity of Hexagon Laboratories, Merck \& Co., and Calco Laboratories of the American Cyanamid Co.

The authors are indebted to Dr. Karl Meyer and to Dr. Charles Ragan for much help and advice, and to Dr. John MacLennon for supplies of some connective tissue derivatives.

\section{REFERENCES}

1. MacLagan, T., The treatment of acute rheumatism by salicin. Lancet, 1876, 1, 342.

2. Hetzel, B. S., and Hine, D. C., The effect of salicylates on the pituitary and suprarenal glands. Lancet, 1951, 2, 94.

3. Van Cauwenberge, H., and Heusghem, C., Acetylsalicylic acid and urinary excretion of adrenocortical steroids. Lancet, 1951, 1, 771.
4. Van Cauwenberge, H., Relation of salicylate action to pituitary gland. Observations in rats. Lancet, 1951, 2, 374.

5. Helander, S., On the distribution of some salicylic acid derivatives in the tissues. Acta pharmacol., 1949, 6, 97.

6. Kapp, E. M., and Coburn, A. F., Urinary metabolites of sodium salicylate. J. Biol. Chem., 1942, 145, 549.

7. Alpen, E. L., Mandel, H. G., Rodwell, V. W., and Smith, P. K., The metabolism of $\mathrm{C}^{\mathbf{1 4}}$ carboxyl salicylic acid in the dog and in man. J. Pharmacol. \& Exper. Therap., 1951, 102, 150.

8. Meyer, K., and Ragan, C., The antirheumatic effect of sodium gentisate. Science, 1948, 108, 281.

9. Camelin, A., Accoyer, P., Pellerat, J., Lafuma, J., and Coirault, R., Action du gentisate de sodium dans la maladie de Bouillard. Premiers essais cliniques. Bull. et mém. Soc. med., d. hôp. de Paris, 1949, 65, 826.

10. Camelin, A., Steiger, R., Morel, M., and Tary, A., Le gentisate de sodium; agent de thérapeutique de la maladie de Bouillard. Presse méd., 1950, 58, 889.

11. Schaefer, L. E., Rashkoff, I. A., and Megibow, R. S., Sodium gentisate in the treatment of acute rheumatic fever. Circulation, 1950, 2, 265.

12. Clarke, N. E., Mosher, R. E., and Clarke, C. N., Phenolic compounds in the treatment of rheumatic fever. I. A study of gentisic acid derivatives. Circulation, 1953, 7, 247.

13. Taggart, J. V., Protein binding of p-aminohippurate in human and dog plasma. Am. J. Physiol., 1951, 167, 248.

14. Roseman, S., and Dorfman, A., The determination and metabolism of gentisic acid. J. Biol. Chem., 1951, 192, 105.

15. Oriekwovitch, V. N., The procollagens, chemical composition, properties, biological role. 2nd Congr. intern. biochim., Chim. biol. II, Symposium biogénèse des protéines (Paris), Paris, 1952, 62.

16. Bergmann, M., and Stein, W. H., A new principle for the determination of amino acids, and its application to collagen and gelatin. J. Biol. Chem., 1939, 128, 217.

17. Hawk, P., Oser, B. L., and Summerson, W. H., Practical Physiological Chemistry. 12th ed., New York, Blakiston, 1947, p. 222.

18. Einbinder, J., and Schubert, M., Binding of mucopolysaccharides and dyes by collagen. J. Biol. Chem., 1951, 188, 335.

19. Evans, W. C., Parr, W. H., and Evans, R. A., Paper partition chromatography of phenolic substances. Nature, 1949, 164, 674.

20. Smith, P. K., Gleason, H. L., Stoll, C. G., and Ogorzalek, S., Studies on the pharmacology of salicylates. J. Pharmacol. \& Exper. Therap., 1946, 87, 237.

21. Ball, E. G., and Chen, T. T., Studies on oxidation- 
reduction. XX. Epinephrine and related compounds. J. Biol. Chem., 1933, 102, 691.

22. Gitlin, D., and Janeway, C. A., The dynamic equilibrium between circulating and extravascular plasma proteins. Science, 1953, 118, 301.

23. Fishberg, E. H., and Dolin, B. T., The biological action of strongly positive oxidation-reduction systems. J. Biol. Chem., 1933, 101, 159.

24. Garrod, A. E., Inborn Errors of Metabolism. 2nd ed., London, H. Froude, 1923.

25. Virchow, R., Ein Fall von Allgemeiner Ochronose der Knorpel und Knorpelähnlichen Theile. Virchows Arch. f. path. Anat., 1866, 37, 212.

26. Neuberger, A., Rimington, C., and Wilson, J. M. G.,
Studies on alcaptonuria. 2. Investigations on a case of human alcaptonuria. Biochem. J., 1947, 41, 438.

27. Consden, R., and Stanier, W. M., Metabolism of gentisic acid. Biochem. J., 1951, 48, xiv.

28. Meyer, K., and Ragan, C., Inhibition of hyaluronidase by hydroquinones and quinones. Federation Proc., 1948, 7, 173.

29. Roseman, S., and Dorfman, A., Effect of gentisic acid and related compounds on bovine testicular hyaluronidase. J. Biol. Chem., 1952, 199, 345.

30. Meyer, K., and Rapport, M. M., Hyaluronidases. Advances in Enzymology, 1952, 13, 199. 